\title{
WARREN DEAN, BRAZILIANISTA BRASILEIRO
}

\author{
Boris Fausto \\ Departamento de Ciências Politicas - FFLCH - USP
}

Conheci Warren Dean por volta de 1967, quando de uma de suas viagens a São Paulo, para completar a redaçāo de seu livro The Industrialization of Sāo Paulo, 1880-1935. Ele teve a gentileza de me emprestar o manuscrito original, datilografado em folhas de papel de seda, naqueles tempos em que ainda não usávamos o computador.

Não sej se esse foj o livro mais importante de Warren, mas foi o que mais me influenciou. Três temas merecem, a meu ver, um destaque especial. O primeiro deles trata das raízes sociais da burguesia industrial paulista, vinculando sua origem ao setor agrário e aos importadores. $O$ nexo entre burguesia agrária e industrial contribuiu para demonstrar a tese da inexistência de profundas contradiçōes entre os dois setores, o que tinha aliás, na época, fortes conseqüências políticas.

A demonstração da existência de uma conexāo entre muitos importadores e a formação da burguesia industrial era absolutamente original. Pouco ou nada se sabia a respeito do papel desempenhado pelos importadores, acreditando-se, de forma impressionista, que eles teriam interesses opostos à industrializaçāo do país, por serem intermediários de bens produzidos no exterior.
Exemplificando com os casos de Crespi, de Muller Carioba e de tantos outros, Warren demonstrou as virtualidades dos importadores para lançarse à produção industrial. Na linha da sua argumentaçāo, por sua própria natureza, a importaçăo requeria certo número de operaçōes a serem realizadas no Brasil. Além disso, o importador, e mais ninguém, possuía todos os requisitos do industrial bem-sucedido: acesso ao crédito, conhecimento do mercado e canais para a distribuição do produto acabado. Mais ainda, os importadores tinham a possibilidade de converter suas agências de vendas em fábricas autorizadas.

Com a vantagem permitida pelo correr dos anos, é possível hoje dizer que o livro deixou apenas de enfatizar suficientemente a importância de imigrantes de classe média baixa - os donos de fabriquetas de fundo de quintal - para a formação do empresariado industrial, como trabalhos posteriores revelaram.

Outra contribuição significativa do texto reside na análise das vinculaçōes entre a Primeira Guerra Mundial e o impulso à industrialização. De forma simplista, estabelecia-se uma correlaçāo positiva 
entre os dois termos, concluindo-se que, a quase interrupção do comércio internacional, gerada pelo conflito, representava uma barreira protecionista, impulsionadora do crescimento industrial do pais. Simplificando sua argumentação, Warren ponderou que tal crescimento dependia de bens de produção importados, razāo principal para que a guerra tivesse efeitos contraditórios que ele considerava mais negativos do que positivos, no contexto dos anos dez.

Essa constatação, embora sujeita a controvérsias, tcm importantes implicações não só com relação à conjuntura estudada por Warren, mas também com rclaçāo à inaugurada pelo início da Segunda Guerra Mundial. Nesse caso, é inequívoco que o impulso à industrializaçāo, por substituição de importaçōes, foi um fenômeno concentrado nos últimos anos do conflito, quando se supcrou, $\mathrm{cm}$ parte, o desarranjo do comércio internacional e os efeitos do fim das relações comerciais com a Alemanha.

Um tercciro tema deve ser destacado e este me tocou diretamente. Trata-se da análise do governo de Getúlio Vargas, nos primeiros anos da década de trinta. Warren sustentou a tese de que o governo nascido da revolução de 1930 foi errático na sua política de apoio aos diferentes setores econômicos, até o advento do Estado Novo, sem privilcgiar portanto a burguesia industrial. Mostrou ainda como, na área da criação de uma infra-estrutura básica de bens c de serviços, o papel largamente predominante foi desempenhado pelo Estado c não pelo setor empresarial privado. Um exemplo, entre vários outros, é o da instalaçāo da Usina da Volta Redonda que os industriais paulistas aplaudiram, mas como meros acompanhantes à distância.

As constataçōes do livro de Warren tiveram um forte impacto na formulação de meu ensaio sobre a Revolução de 1930, que vinha redigindo naquela altura. Senti-me reforçado, pela afirmação implícita da inexistência de contradiçōes frontais entre a burguc- sia agrária e a industrial - setores sociais muitas vezes imbricados - o que conduzia a uma interpretaçăo diversa da traúicional, acerca das forças sociais integrantes da revoluçāo de 1930. Especificamente, pude dar maior concreçāo à tese de que o impulso básico à industrialização não provinha de um setor da sociedade e sim do Estado.

Hoje, passados 25 anos, várias afirmações dos textos de Warren e dos meus já nāo sc sustentam inteiramentc, ou precisam ser matizadas. Mas clas abriram caminho, scm falsa modéstia, para se repensar as características da industrializaçāo brasilcira $\mathrm{e}$, em nível mais amplo, para se repensar a natureza das classes sociais, assim como a natureza das rclações entre classe social c Estado.

Warren integrou a espécie brazilianistas, os quais tem em comum, como se sabe, o fato de serem pesquisadores estrangciros, sobretudo americanos, especialistas em temas brasileiros. Hoje, a controvérsia sobre os brazilianistas perdeu sentido e cles próprios se converteram em uma espécie com poucos exemplares, talvez destinada à extinção. Não era assim nos anos sessenta e setenta, quando seus adversários thes atiravam à cara várias pechas. Elas iam desde a relativamente suave acusação de que estariam concorrendo, $\mathrm{cm}$ condiçōes vantajosas, com colegas brasileiros, por terem acesso a uma documentação inacessível para estes, até as invectivas de que punham em perigo a história nacional, sendo em alguns casos, suspcitos de serem agentes da CIA.

Năo posso garantir que a última referência fossc em todos os casos inverídica, mas certamente eles nāo puseram em risco a memória pátria e, só $\mathrm{cm}$ alguns casos de fontes relativas à açāo do aparelho repressivo, ou às Forças Armadas, pequisaram $\mathrm{cm}$ condiçôes privilegiadas, em comparação com seus colcgas brasileiros.

A verdade é que se uma caracterizaçăo genérica permite definir a espécie dos brazilianistas, seus integrantes variavam e ainda variam, na medida dos 
traços pessoais e da qualidade intelectual. No que diz respeito às características pessoais, é possível falar de uma seqüência que ia, em um extremo, daqueles que vislumbravam nos colegas brasileiros meros informantes, até aqucles que, em outro extremo, levavam a sério os pesquisadores de nosso país, interessavam-se pelo que aqui ocorria, estabelecendo também muitos laços de amizade.

Warren era uma figura exemplar deste último grupo. Na área da atividade pública, com a discrição que lhe era peculiar, denunciou, ao lado de outros intelectuais americanos, violências praticadas contra professores brasileiros, e a prática da tortura, durante o regime militar.

Tive também a oportunidade de constatar como levava a sćrio scus colegas brasileiros quando, aí pelo ano de 1986, o encontrei em Nova York. Naquela altura, bascando-se na ascensão de Jânio e de Brizola, aliás mais efêmera do que imaginava, ele me disse, meio interrogativo: " - Então você estava errado com rclação à morte do populismo?" Achei a pergunta estranha, pois nāo me lembrava de ter feito a "profecia". Warren me recordou entäo, que ela constava de uma entrevista, meio despreocupada, que eu dera para uma publicaçāo avulsa da Editora Brasiliense.

Voltando aos anos sessenta, lembraria que Warren e os brazilianistas me influenciaram decisivamente, sob o ponto de vista metodológico; acredito mesmo que essa influência nāo se restringiu à minha pessoa. Quero me referir a uma coisa óbvia, ou seja, à necessidade do ofício de historiador se assentar em um sólido material empírico. Naqueles anos, como resultado de uma produçāo historiográfica de um raso estilo narrativo, hesitava em esmiuçar os "fatos da história". Ao mesmo tempo, tinha muito respeito, mas ncnhum .encanto, pelas grandes explicaçōes sociológicas que eram entāo prestigiosa moeda corrente.

Não foi propriamente um brazilianista quem pro- porcionou "a chave da mina" c sim um intelectual inglês, ocasionalmente interessado na História do Brasil: Perry Anderson, um dos editores na New Left Review, detentor, por ser marxista, de um selo de legitimidade. Estudando os anos vinte e o contexto sóciopolítico que deu origem à Revoluçāo de 1930, Perry valorizava tanto a macroestrutura quanto acóntecimentos na aparência banais, mas cheios de significado. Por exemplo, para demonstrar o conservadorismo das elites oligárquicas dissidentes, lembrava o excmplo do presidente de Minas, Olegário Maciel, que nāo ousava sequer proferir a palavra "revolução", designando-a sempre como "a coisa".

O selo marxista era indispensável, naquela época, para autorizar o ingresso no mundo empírico. Mas foram os brazilianistas de qualidade - entre os quais se encontrava, na primeira fileira, Warren Dean - os responsáveis pela elaboração de um tipo de história que punha os pés no chão escorregadio do passado. Por certo eles năo eram muito fortes em teorias explicativas mas, naquela altura, sc me permitem o plural, estávamos mais carentes do conhecimento de processos, episódios, instituiçōes, do que de delinear grandes abstrações.

Quando pessoas amigas se vão de forma inesperada, fica nítida a imagem da "última vez", que nāo imaginávamos fosse a última. Foi assim com Joaquim Barradas de Carvalho, històriador da História da Cultura Portuguesa, de quem me despedi para sempre, no corredor de um hotel lisbocta, fazendo planos recíprocos para o futuro.

Foi assim também com Warren, de quem me despedi, depois de um almoço, em um restaurante indiano do Village, sua "cidade" natal, por opção. Durante o almoço ele corrigiu, com elegância, comentários apressados que eu fazia sobre a estrutura universitária americana. Falou mais do que costumava, demons- 
trando entusiasmo pela opção pioneira que fizera nos últimos tempos, concentrando-se na história ambiental da América Latina. Nāo quero porém insis- tir na nostalgia, pois poderia descambar na retórica, falha que certamente Warren censuraria com seu olhar irônico. 